Mini Review

\title{
Improving Methods for better Performance of Commercial $\mathrm{LiFePO}_{4} / \mathrm{C}_{\text {Batteries }}$
}

\author{
Shaoqing Zhu', Aoming Huang ${ }^{2}$, Ye Xu ${ }^{1, *}$ \\ ${ }^{1}$ School of Mechanical Engineering \& Automation, Beihang University, Beijing 100191, China \\ ${ }^{2}$ School of Physical and Mathematical Science, Nanjing Tech University (NanjingTech), Nanjing \\ 211800, China \\ *E-mail: ye.xu@buaa.edu.cn
}

doi: $10.20964 / 2021.05 .49$

Received: 23 November 2020 / Accepted: 23 February 2021 / Published: 31 March 2021

Olivine-type lithium iron phosphate $\left(\mathrm{LiFePO}_{4}\right)$ electrodes had the advantages of low cost, low toxicity, and high theoretical capacity, and have attracted the attention of those engaged in mass-production of commercial lithium ion batteries (LIBs). $\mathrm{LiFePO}_{4} / \mathrm{C}$ secondary batteries were widely used in mobile devices, electric vehicles (EV) and energy storage power stations, and exhibited high energy density, stable cycle performance and low self-discharge rate at room temperature. However, $\mathrm{LiFePO}_{4} / \mathrm{C}$ batteries suffered from rapid capacity deterioration at extreme low/high temperatures, which significantly limited their further commercial application. Therefore, it was of great significance to systematically summarize the accelerated fading mechanism of $\mathrm{LiFePO}_{4} / \mathrm{C}$ batteries under extreme temperatures and the progress of the modification strategies. In this review, the degradation mechanism of $\mathrm{LiFePO}_{4} / \mathrm{C}$ batteries at extreme low and high temperatures were discussed. Corresponding strategies in improving the electrochemical properties of $\mathrm{LiFePO}_{4} / \mathrm{C}$ battery under these extreme conditions, including electrolyte optimization and cathode modification, were then grouped. Finally, several viewpoints were summarized based on the current progress, aiming to provide possible methods and research suggestions to enhance the practicality of commercial $\mathrm{LiFePO}_{4} / \mathrm{C}$ batteries at extreme temperature conditions in the future.

Keywords: Lithium ion batteries, $\mathrm{LiFePO}_{4}$, temperature, fading mechanism, improving strategies

\section{$\underline{\text { FULL TEXT }}$}


(C) 2021 The Authors. Published by ESG (www.electrochemsci.org). This article is an open access article distributed under the terms and conditions of the Creative Commons Attribution license (http://creativecommons.org/licenses/by/4.0/). 